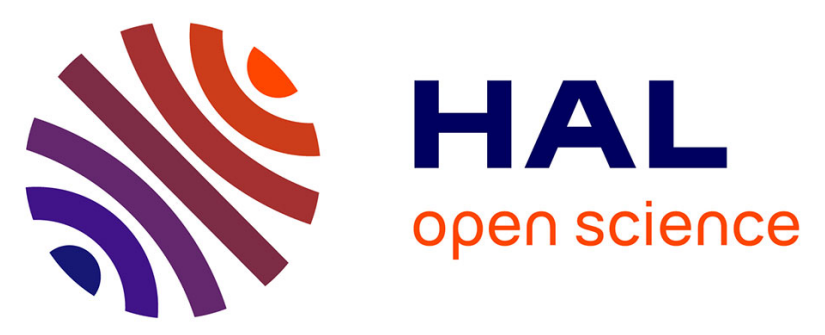

\title{
Titration of aqueous solutions of phenols and determination of their bromination rate constants by means of ring-disc electrodes
}

Francis Rauwel, Daniel R. Thevenot

\section{- To cite this version:}

Francis Rauwel, Daniel R. Thevenot. Titration of aqueous solutions of phenols and determination of their bromination rate constants by means of ring-disc electrodes. Journal of Applied Electrochemistry, 1976, pp.119 - 126. 10.1007/BF00615376 . hal-01178845

\section{HAL Id: hal-01178845 \\ https://hal.science/hal-01178845}

Submitted on 21 Jul 2015

HAL is a multi-disciplinary open access archive for the deposit and dissemination of scientific research documents, whether they are published or not. The documents may come from teaching and research institutions in France or abroad, or from public or private research centers.
L'archive ouverte pluridisciplinaire $\mathbf{H A L}$, est destinée au dépôt et à la diffusion de documents scientifiques de niveau recherche, publiés ou non, émanant des établissements d'enseignement et de recherche français ou étrangers, des laboratoires publics ou privés. 


\title{
Titration of aqueous solutions of phenols and determination of their bromination rate constants by means of ring-disc electrodes
}

\author{
F. RAUWEL, D. THÉVENOT \\ Laboratoire d'Energétique Biochimique, Université Paris - Val de Marne, 94000 Creteil, France.
}

Received 21 January 1975

The use of ring-disc electrodes enables the detection of metacresol, resorcinol, orcinol, phloroglucinol and pyrogallol at concentrations down to $10^{-7} \mathrm{M}$ and generally the titration of these compounds with an accuracy of a few percents when the concentrations are larger than about $5 \times 10^{-6} \mathrm{M}$. Phenol, orthoand para-cresol can be titrated at concentrations larger than about $5 \times 10^{-5} \mathrm{M}$. On the other hand, bromination rate constant determinations have been carried out with phenol, ortho- and meta-cresol.

\section{Introduction}

The use of ring-disc electrodes may be a convenient method for the titration of compounds which can rapidly react with electrochemicaly generated species. We have applied it to several phenols which can be substituted rapidly by bromine.

Bromine is generated on the disc by oxidation of bromide contained in the solution:

$$
\text { (disc) } 2 \mathrm{Br}^{-} \longrightarrow \mathrm{Br}_{2}+2 \mathrm{e}^{-} \text {. }
$$

Because of the rotation of the electrode, the nascent bromine reaches the ring which is set at a suitable potential for the complete reduction of bromine:

$$
\text { (ring) } \mathrm{Br}_{2}+2 \mathrm{e}^{-} \longrightarrow 2 \mathrm{Br}^{-} \text {. }
$$

If the solution is free of chemicals which can react with bromine during its transit from disc to ring, the observed ring current $I_{\mathrm{r}}$ is proportional to the monitored disc current $I_{\mathrm{d}}$. If chemicals such as phenols are present in the solution, bromine reacts before reaching the ring. The shape of the $I_{\mathrm{r}}$ versus $I_{\mathrm{d}}$ titration curves, then, gives two kinds of information: the concentration level of the compound reacting with bromine and the bromination rate.

\section{Titrations}

If the bromination reaction is very fast, $I_{\mathrm{r}}$ versus $I_{\mathrm{d}}$ curves have the shapes of curves 1 and 2 of Fig. 1. The concentration of the titrated compound $C$ can be easily obtained from the value $I_{\mathrm{d}, 0}$ of $I_{\mathrm{d}}$ at which the asymptote crosses the $I_{\mathrm{d}}$ axis. Bruckenstein and Johnson [1] have shown that this value is proportional to $C$, and the ratio between $I_{\mathrm{d}, 0}$ and $C$ can be either calculated or determined with solutions of known concentration. $C$ can alternatively be obtained by the mathematical analysis of the whole titration curve 2: this second method which eliminates extrapolation uncertainties is assumed to be more accurate than the first one.

If the reaction rate between the titrated compound and the intermediate generated on the disc is not high enough, the slope of the $I_{\mathrm{r}}$ versus $I_{\mathrm{d}}$ curve is different from zero at low values of $I_{\mathrm{d}}$. As this slope depends on $C$ [3a], titration is still possible. But the slope also depends on the reaction rate which is generally unknown. The easiest way to determine $C$ is therefore to calibrate the $I_{\mathrm{r}}$ versus $I_{\mathrm{d}}$ curves by comparison with those obtained with solutions of known concentration. 


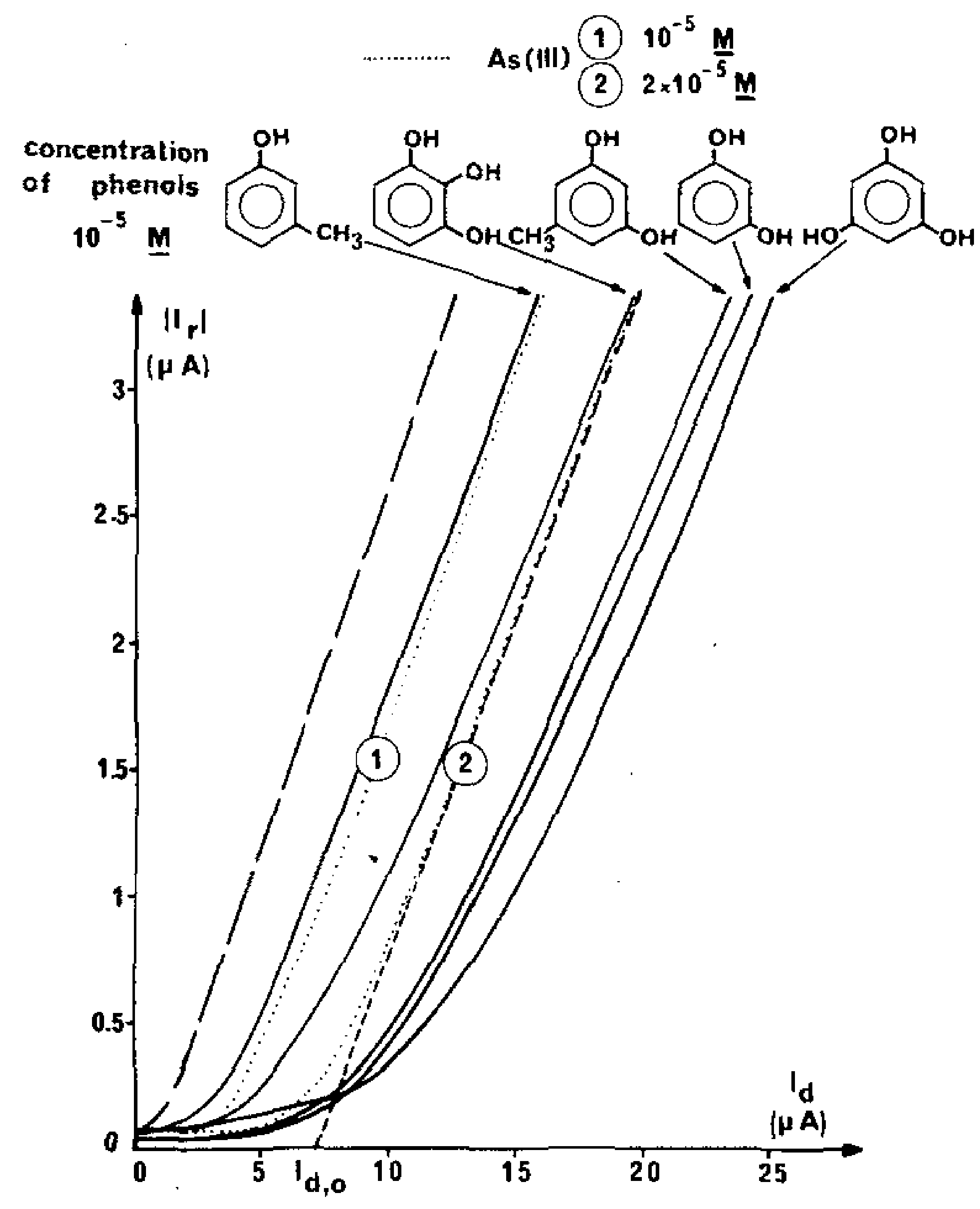

Fig. 1. Titration curves of $10^{-5} \mathrm{M}$ solutions of m.cresol, pyrogallol, orcinol, resorcinol and phloroglucinol; comparison curves $(\ldots \ldots \ldots)$ with $10^{-5} \mathrm{M}(1)$ and $2 \times 10^{-5} \mathrm{M}$ (2) As (III) solutions. Gold ring-carbon disc electrode (No. 1), $\mathrm{H}_{2} \mathrm{SO}_{4} 1 \mathrm{~N}, \mathrm{Br}^{-} 0.5 \mathrm{M}, W=28.6 \mathrm{~Hz}, 25^{\circ} \mathrm{C}$.

2.1. Resorcinol (dihydroxy 1, 3 benzene), phloroglucinol (trihydroxy 1, 3, 5 benzene), orcinol (methyl 5, dihydroxy 1, 3 benzene), pyrogallol (trihydroxy 1,2, 3 benzene) meta-cresol (methyl 3 , phenol)

With these compounds, $I_{\mathrm{r}}$ versus $I_{\mathrm{d}}$ curves (Fig. 1) seem to have the general shape expected for fast reactions, but the mathematical analysis of these curves shows that they cannot be described by the theoretical equations established by Albery, Bruckenstein and Johnson [2]. This is certainly due to a rather low rate of the bromination reaction and/or to the oxidation of the titrated compound on the disc, simultaneously with bromine. We have checked with our electrodes that $I_{\mathrm{r}}$ versus $I_{\mathrm{d}}$ curves obtained with As (III) and allyl-alcohol (compounds previously used to control the method) $[2,4]$ were in good agreement with the theoretical equations.

With all compounds, the asymptotical part of the curves is reached at a rather high $I_{\mathrm{d}}$ and, therefore, titrations by means of this method of determination of $C$ may not be very accurate. We therefore compared the experimental curves with those

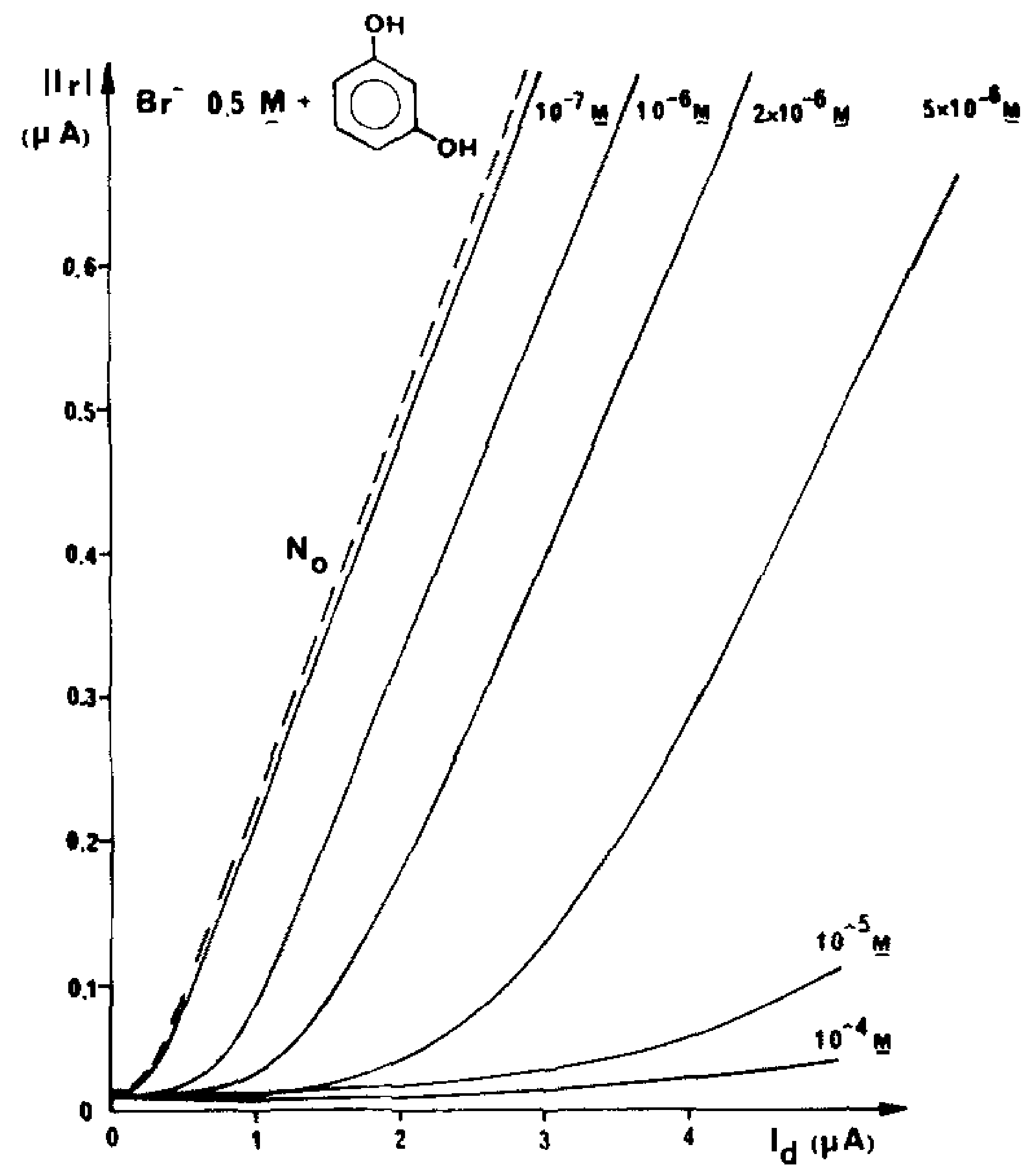

Fig. 2. Titration curves of resorcinol. Gold ring-carbon disc electrode (No. 1 ), $\mathrm{H}_{2} \mathrm{SO}_{4} 1 \mathrm{~N}, \mathrm{Br}^{-} 0.5 \mathrm{M}, W=$ $28.6 \mathrm{~Hz}, 25^{\circ} \mathrm{C}$.

obtained with solutions of known concentration.

\subsubsection{Resorcinol, phloroglucinol and orcinol.}

These compounds react rather rapidly with bromine because they have substitution sites activated by at least two hydroxy-groups.

The comparison of the $I_{\mathrm{r}}$ versus $I_{\mathrm{d}}$ curves corresponding to these phenols with those obtained with As (III) at the same concentration or at a concentration two times larger shows that these compounds undergo three following rapid brominations (Fig. 1) and perhaps other extrabrominations for resorcinol and phloroglucinol (this last phenol is known to react with six moles of $\mathrm{Br}_{2}$ when titrated with this compound [5]). With these three phenols, curves start to deviate from the blank straight line when $C$ is larger than about $10^{-7} \mathrm{M}$; titrations can be achieved with an accuracy of a few per cent when $C$ is larger than about $5 \times 10^{-6} \mathrm{M}$ (Fig. 2).

2.1.2. Pyrogallol. Pyrogallol also has substitution sites activated by two hydroxy-groups and therefore also reacts rapidly with bromine. The sensitivity of the method is somewhat lower than with resorcinol, orcinol and phloroglucinol because only two brominations occur (Fig. 1), one site being already substituted.

Titration curves may exhibit a peak at low 


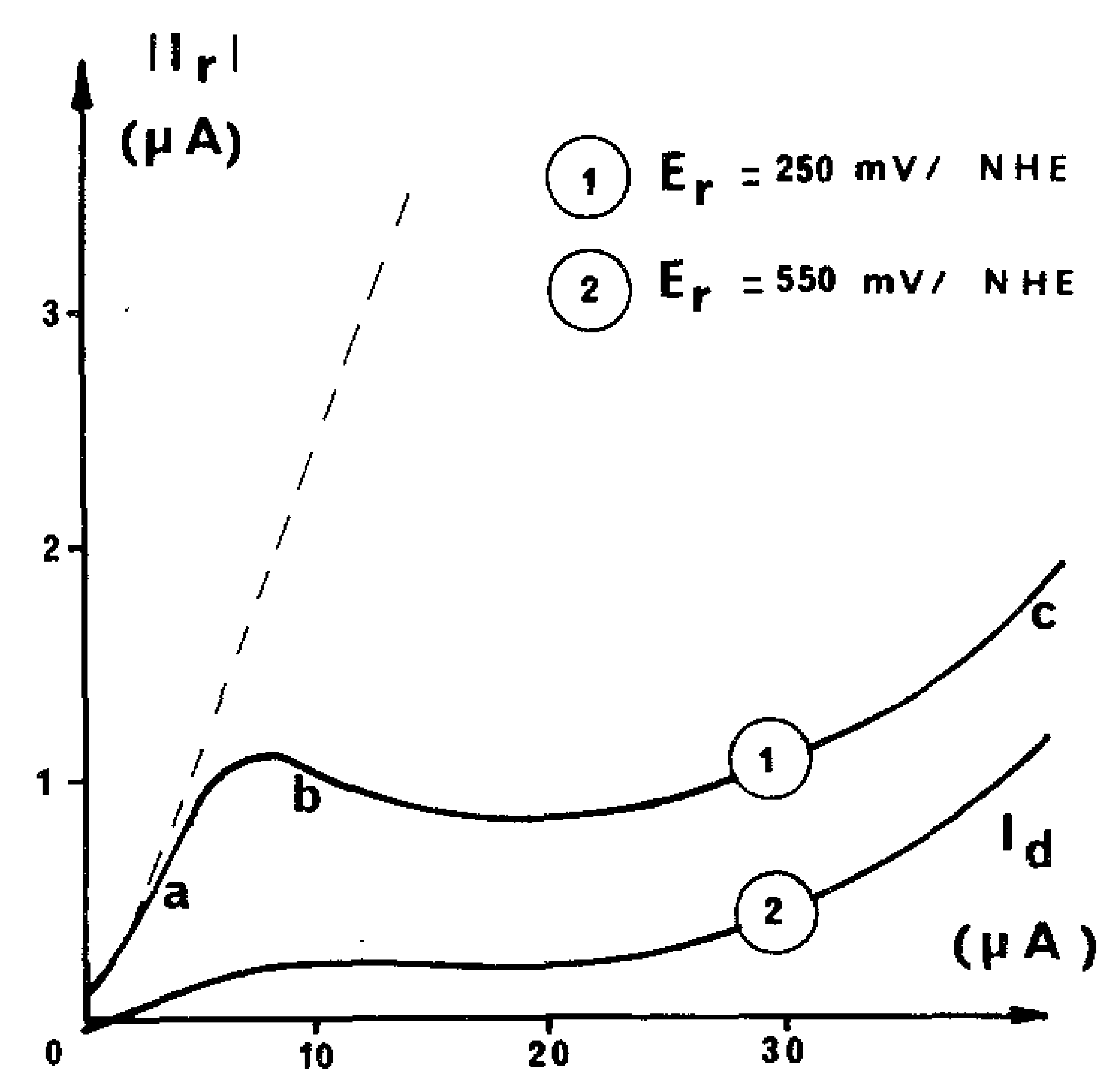

Fig. 3. $I_{\mathrm{r}}$ versus $I_{\mathrm{d}}$ curves obtained with a solution of pyrogallol $10^{-4} \mathrm{M}$ with two different ring potentials: (1) 0.25 and (2) 0.55 V/N.H.E. Gold ring-carbon disc electrode (No. 1), $\mathrm{H}_{2} \mathrm{SO}_{4} 1 \mathrm{~N}, \mathrm{Br}^{-} 0.5 \mathrm{M}, W=28 \cdot 6 \mathrm{~Hz}$, $25^{\circ} \mathrm{C}$.

values of $I_{\mathrm{d}}$ when the ring potential is low enough (Fig. 3, curve 1). This peak results from the interference of two phenomena: (1) the reaction of pyrogallol with the nascent bromine; (2) the oxidation of pyrogallol on the disc and the detection on the ring of its oxidation product.

Current-potential curves obtained with solutions of pyrogallol and bromide show that, at low values of $I_{\mathrm{d}}$, pyrogallol is oxidized instead of bromide. $I_{\mathbf{r}}$ is different from zero (Fig. 3, part a of curve 1) because the oxidation product of pyrogallol is reducible on the ring. When $I_{\mathrm{d}}$ is larger than the limiting diffusion current of pyrogallol, bromine is generated and reacts with pyrogallol. The number of pyrogallol molecules reaching the disc then decreases, and therefore the number of molecules which results from the oxidation of pyrogallol also decreases. Therefore $I_{\mathrm{r}}$ decreases (Fig. 3, part b of curve 1). When $I_{\mathrm{d}}$ is large enough, bromine is generated in excess and prevents pyrogallol molecules from reaching the disc: the behaviour is then as if pyrogallol could not be oxidized on the disc (Fig. 3, part c of curve 1).

It is possible to remove such a peak from the $I_{\mathrm{r}}$ versus $I_{d}$ curves by monitoring the ring potential at a value low enough to allow the complete reduction of bromine, but high enough to prevent the oxidation product of pyrogallol from being detected on the ring (Fig. 3, curve 2).
Table 1. Concentration ranges in which various phenols can be titrated at $0^{\circ} \mathrm{C}$ using the slope $N_{\mathrm{K}}$ of the $I_{\mathrm{r}}$ versus $I_{\mathrm{d}}$ lines

\begin{tabular}{lll}
\hline & $\begin{array}{l}C_{\min } \\
(\mathrm{M})\end{array}$ & $\begin{array}{l}C_{\max } \\
(\mathrm{M})\end{array}$ \\
\hline Anisole & $8 \times 10^{-5}$ & $7 \times 10^{-2}$ \\
Phenol & $7 \times 10^{-6}$ & $6 \times 10^{-3}$ \\
Ortho-cresol & $2 \times 10^{-6}$ & $2 \times 10^{-3}$ \\
Meta-cresol & $1.5 \times 10^{-7}$ & $1.5 \times 10^{-4}$ \\
\hline
\end{tabular}

Concentration limits determined by $0.1 N_{0}<$ $N_{\mathrm{K}}<0.9 N_{0}$ for platinum-platinum ring-disc electrode No. 2 and for a rotation speed range $4-80 \mathrm{~Hz}$.

2.1.2. Meta-cresol. The detection limits are somewhat higher than with the previous phenols, for this compound undergos only one rapid bromination in the time scale of the transit time from disc to ring (Fig. 1). This confirms that the mesomer effect of the OH-entity is larger than the inductive effect of the $\mathrm{CH}_{3}$-group.

\subsection{Phenol, ortho- and para-cresol}

These compounds react more slowly with bromine than the previous ones. This is the reason why the slopes of the $I_{\mathrm{r}}$ versus $I_{\mathrm{d}}$ curves are different from zero even when $C$ is as large as $10^{-4} \mathrm{M}$ and when the rotation speed $W$ of the electrode is low (Fig. 4). The relative positions of the curves shows that the bromination rate increases according to:

$$
\text { phenol < para-cresol < ortho-cresol. }
$$

In the next paragraph we give an estimate of these reaction rates.

Even in very acidic media, these phenols are oxidized on solid electrodes at potentials which are very near the oxidation potential of bromine. As their oxidation products spoil the surfaces of the electrode [6], no reproducible curves can be obtained when $I_{\mathrm{d}}$ is too large. Thus it is generally not possible to reach the asymptotical parts of the curves. This does not occur with metacresol which reacts at least ten times more rapidly with bromine (see later) because in this case bromine prevents molecules of meta-cresol from reaching the disc and interfering with the desired reaction.

However, for low $I_{\mathrm{d}}, I_{\mathrm{r}}$ versus $I_{\mathrm{d}}$ curves are 


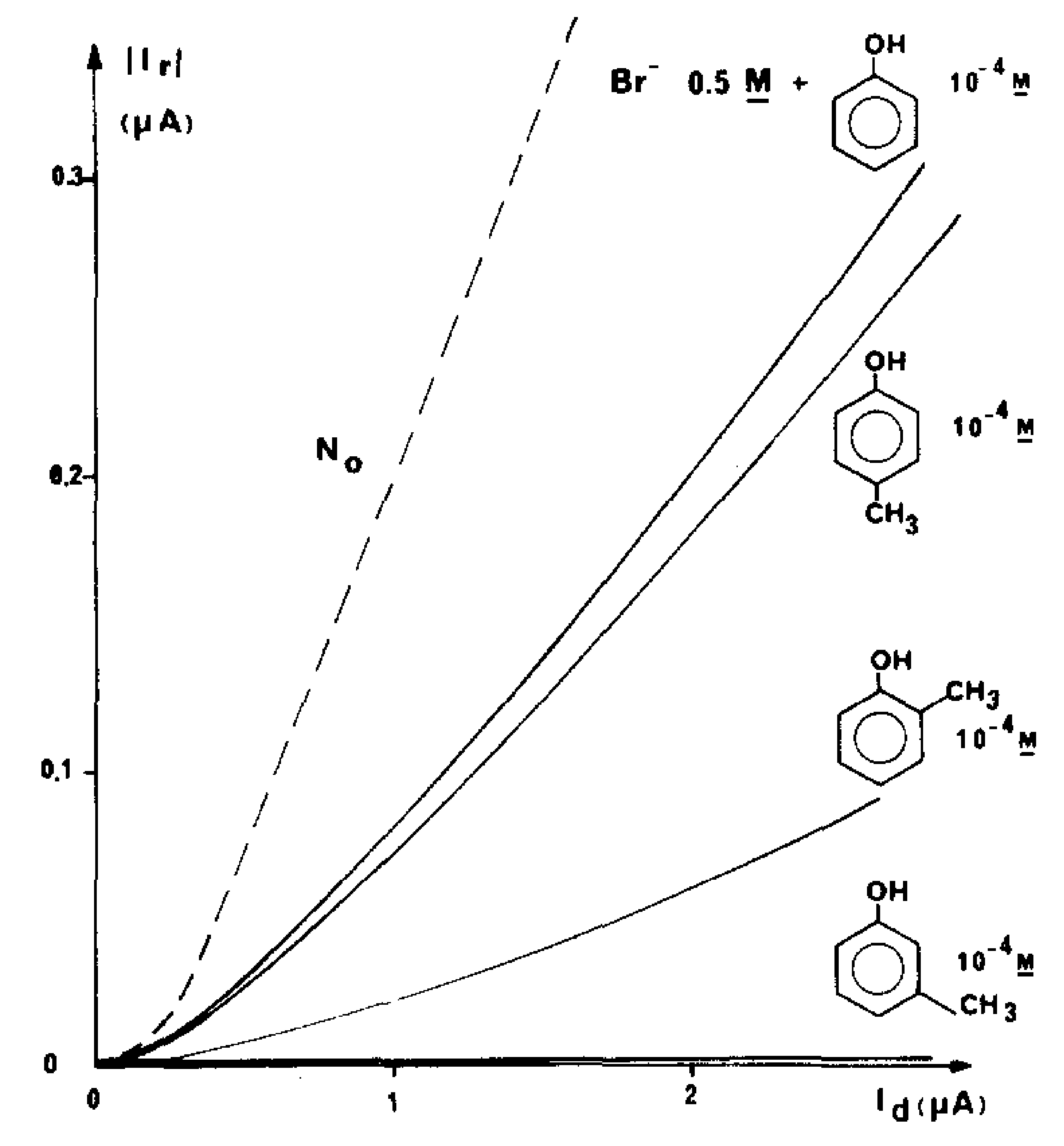

Fig. 4. $I_{\mathbf{r}}$ versus $I_{\mathrm{d}}$ curves obtained with $10^{-4} \mathrm{M}$ solutions of phenol, para-, ortho-, and meta-cresol. Gold ringcarbon disc electrode (No. 1), $\mathrm{H}_{2} \mathrm{SO}_{4} 1 \mathrm{~N}, \mathrm{Br}^{-} 0.5 \mathrm{M}$, $W=28.6 \mathrm{~Hz}, 25^{\circ} \mathrm{C}$.

reproducible and depend on $C$. Titrations are therefore possible but the slope $N_{\mathrm{K}}$ at $I_{\mathrm{d}}=0$, which depends also on $W$ and the bromination kinetics, must be significantly different from zero and from $N_{0}$. Table 1 presents, for one of our electrodes, the concentration ranges of these phenols which give

$$
0 \cdot 1 N_{0}<N_{\mathrm{K}}<0.9 N_{0}
$$

$W$ being taken in the range $4-80 \mathrm{~Hz}$. In these conditions, the accuracy of the titrations is about 10-20\%, when the $I_{\mathrm{r}}$ versus $I_{\mathrm{d}}$ curves are linear enough i.e. when $C$ is larger than about $2 \times 10^{-6} \mathrm{M}$.

\subsection{Hydroquinone.}

$I_{\mathrm{r}}$ versus $I_{\mathrm{d}}$ curves have the usual shapes of the titration curves obtained with chemicals which react very rapidly with bromine, but the value $I_{\mathrm{d}, 0}$ of $I_{\mathrm{d}}$ at which the asymptotical part of the curve crosses the $I_{\mathrm{d}}$ axis is much smaller than predicted by the theory, and the slope of the curves near the origin may not be equal to zero. In fact, the shape of the curves is not related to the bromination of hydroquinone (the rate of which is not high enough though the reaction seems instantaneous when solutions of these compounds are mixed), but to its oxidation on the disc prior to the oxidation of bromide. This appears clearly on the current-potential curves of solutions of both hydroquinone and bromine: at low $I_{\mathrm{d}}$, hydroquinone is oxidized instead of bromine and the limiting diffusion-current has approximately the same value as $I_{\mathrm{d}, 0}$. As $I_{\mathrm{r}}$ versus $I_{\mathrm{d}}$ curves depend on $C$, titrations are still possible, but the detection limits and the accuracy of the method are those of simple voltammetry on a rotating disc electrode.

The slopes of the $I_{\mathrm{r}}$ versus $I_{\mathrm{d}}$ curves may not be equal to zero when $I_{\mathrm{d}}$ is smaller than $I_{\mathrm{d}, 0}$ because, as with pyrogallol, the oxidation product of hydroquinone may be detected on the ring.

\section{Bromination rate constant determinations}

\subsection{Theory}

When the intermediate species generated on the disc reacts by a first-order or a second-order reaction, the reaction rate constant may be calculated $[3 a, b]$.

\subsubsection{First-order bromination reactions. When the} concentration level of the electrochemically generated species is low enough in comparison with $C$ near the electrode, second order reactions, the rate of which can be written

$$
-\frac{d\left(\mathrm{Br}_{2}\right)}{\mathrm{d} t}=k_{2}\left(\mathrm{Br}_{2}\right) C
$$

become apparent first-order reactions, $k_{2} C$ being constant. With low values of $I_{\mathrm{d}}, I_{\mathrm{r}}$ versus $I_{\mathrm{d}}$ plots are straight lines, the slopes of which, $N_{\mathrm{K}}$, depend on the rotation speed $W$, on $k_{2}$, on $C$, and on the characteristics of the electrode. But the curve $N_{\mathrm{K}}$ versus $K$ with

$$
K=0.499, \nu^{\frac{1}{6}} D^{-\frac{1}{6}} k_{2}^{\frac{1}{2}} C^{\frac{1}{2}} W^{-\frac{1}{2}}
$$

depends only on the geometrical parameters of the electrode. Then the comparison of the experimental curve $N_{\mathrm{K}}$ versus $C^{\frac{1}{2}} W^{-\frac{1}{2}}$ with the theoretical $N_{\mathrm{K}}$ versus $K$ curve calculated for the electrode gives $k_{2}$ when $\nu$ and $D$ are known.

In fact, $N_{\mathrm{K}}$ versus $C^{\frac{1}{2}} W^{-\frac{1}{2}}$ curves (Fig. 5) were compared with only a part of the theoretical one, an approximate expression of which is

$$
\log N_{\mathrm{k}}=\log N_{\mathbf{0}}-a K+b-\log \left(1+\frac{1}{K+c}\right)
$$


Table 2. Geometrical characteristics of ring-disc electrodes used - calculated and measured collection efficiency $N_{0}$ - values of coefficients $a, b$ and $c$ used in the analytical expression of $N_{\mathrm{K}}$ as a function of $K$

\begin{tabular}{lll}
\hline & $\begin{array}{l}\text { Gold-ring } \\
\text { carbon-disc } \\
\text { electrode } \\
\text { (No. 1) }\end{array}$ & $\begin{array}{l}\text { Platinum-ring } \\
\text { platinum-disc } \\
\text { electrode } \\
\text { (No. 2) }\end{array}$ \\
\hline$r_{1}$ (radius of disc electrode) & $1.37 \pm 0.04 \mathrm{~mm}$ & $3.56 \pm 0.06 \mathrm{~mm}$ \\
$r_{2}$ (inner radius of ring electrode) & $1.65 \pm 0.04 \mathrm{~mm}$ & $3.73 \pm 0.06 \mathrm{~mm}$ \\
$r_{3}$ (outer radius of ring electrode) & $1.91 \pm 0.04 \mathrm{~mm}$ & $4.77 \pm 0.05 \mathrm{~mm}$ \\
Calculated $N_{0}$ & $0.269 \pm 0.020$ & $0.398 \pm 0.015$ \\
Observed $N_{0}$ & $0.280^{*} \pm 0.006$ & $0.401 \pm \pm 0.011$ \\
a & - & 2.08 \\
$\mathrm{~b}$ & - & 1.74 \\
$\mathrm{c}$ & - & -0.18 \\
\hline
\end{tabular}

${ }^{*}$ Average of eight experiments at $W=28.6 \mathrm{~Hz}, \mathrm{Br}^{-} 0.5 \mathrm{M}$ and ring-potential $+0.45 \mathrm{~V} /$ N.H.E. with $\mathrm{Br}_{2} / \mathrm{Br}^{-}$system.

$\dagger$ Theoretical equation from [3d]

\# Average of eight experiments at various $W,\left(\mathrm{Br}^{-}\right)$, and ring-potential $+0.2 \mathrm{~V} /$ N.H.E., with $\mathrm{Br}_{2} / \mathrm{Br}^{-}$system.
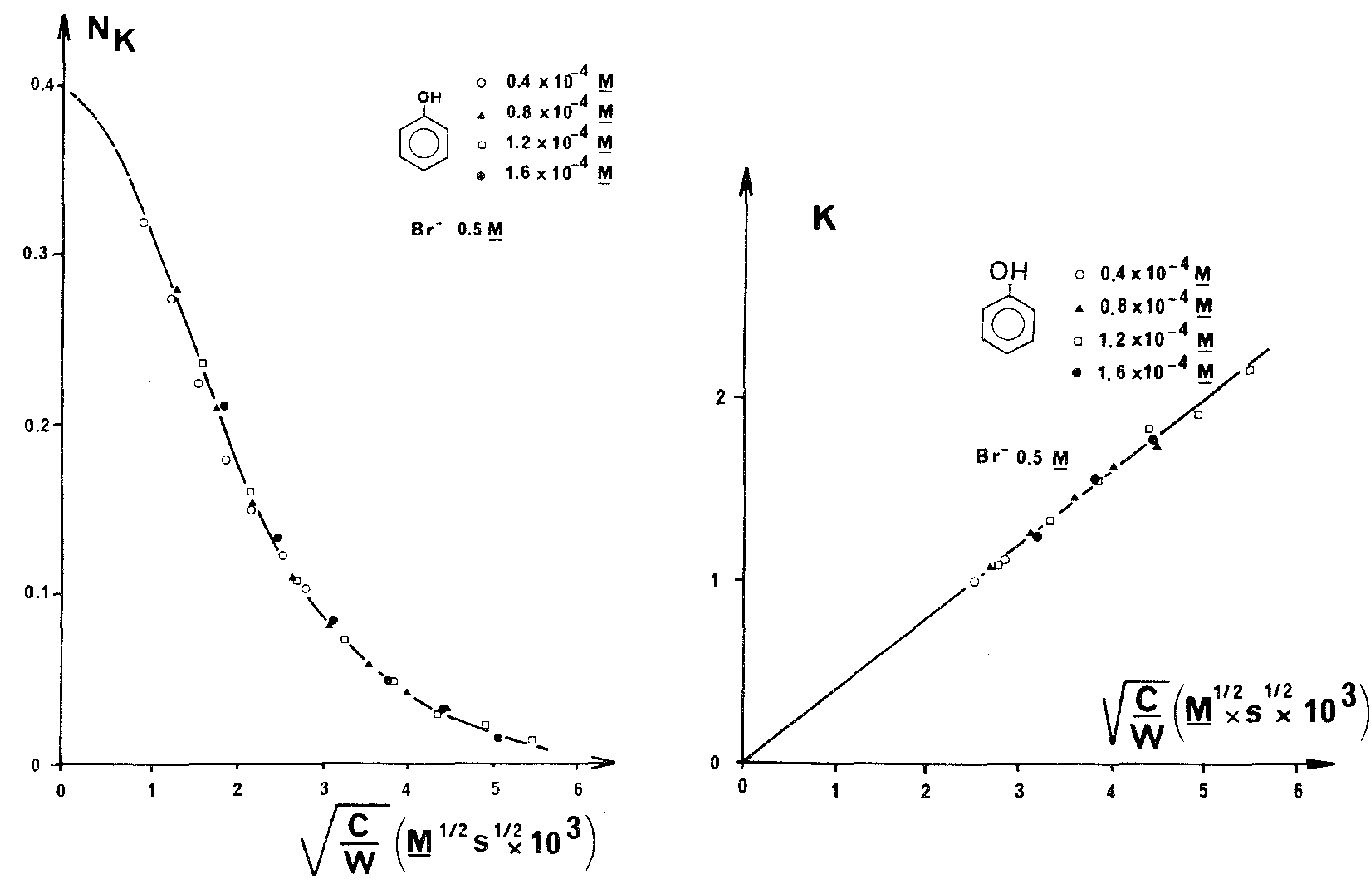

Fig. 5 and 6. Apparent first-order rate constant determination: bromination of phenol. $W$ range $4-50 \mathrm{~Hz}$. Platinum ring-platinum disc electrode (No. 2), $\mathrm{H}_{2} \mathrm{SO}_{4} 1 \mathrm{~N}, \mathrm{Br}^{-} 0 \cdot 1 \mathrm{M}, 25^{\circ} \mathrm{C}$.

Fig. 5. Experimental slope $N_{\mathrm{K}}$ versus $C^{\frac{1}{2}} W^{-\frac{1}{2}}$.

Fig. 6. $K$ versus $C^{\frac{1}{2}} W^{-\frac{1}{2}}$ respectively calculated and measured for observed $N_{\mathrm{K}}$ values.

where $a, b$ and $c$ are numerical constants which have been calculated as a function of the geometrical parameters of the electrode [3c]
(Table 2). Values of $K$, plotted against $C^{\frac{1}{2}} W^{-\frac{1}{2}}$ for various $N_{\mathrm{K}}$ give a straight line, the slope of which is related to $k_{2}$ (Fig. 6). 
Table 3. Overall bromination rates of some compounds. Platinum-platinum ring-disc electrode (No. 2)

\begin{tabular}{llllll}
\hline Compound & $\begin{array}{l}T \\
\left({ }^{\circ} \mathrm{C}\right)\end{array}$ & $\begin{array}{l}\left(\mathrm{Br}^{-}\right) \\
(\mathrm{M})\end{array}$ & $\begin{array}{l}\left(\mathrm{H}^{+}\right) \\
(\mathrm{M})\end{array}$ & $\begin{array}{l}k \\
\left(\mathrm{M}^{-1} \times \mathrm{s}^{-1}\right)\end{array}$ & $\begin{array}{l}\text { Reaction } \\
\text { order }\end{array}$ \\
\hline Anisole & 0 & $0 \cdot 2$ & $10^{-3}$ & $1.4 \times 10^{3}$ & 1 \\
m-cresol & 0 & 0.5 & 2 & $6.8 \times 10^{5}$ & 1 \\
o-cresol & 0 & $0 \cdot 5$ & 2 & $4.6 \times 10^{4}$ & 1 \\
Phenol & 0 & 0.5 & 2 & $1.5 \times 10^{4}$ & 1 \\
& 25 & 0.1 & 1 & $6.4 \times 10^{4}$ & 1 \\
& 25 & $*$ & $0 \cdot 2$ & $1.8 \times 10^{5}(10)$ & \\
Allyl-alcohol & 20 & $0 \cdot 1$ & $5.6 \times 10^{-4}$ & $2 \times 10^{5}$ & 2 \\
& 25 & 0.1 & $5.64 \times 10^{-4}$ & $7.2 \times 10^{5}(3 \mathrm{~b})$ & 2 \\
\hline
\end{tabular}

* extrapolation to $\left(\mathrm{Br}^{-}\right)=0$

3.1.2. Second-order bromination reactions. When $k_{2}$ is very high, the reacting compounds cannot exist simultaneously outside of a narrow volume at the border of two regions: one where bromine alone is present and one where the compound reacting with bromine alone is present. $\left(\mathrm{Br}_{2}\right)$ and $C$ vary around the electrode and the reaction is really second-order.

$I_{\mathrm{r}}$ versus $I_{\mathrm{d}}$ curves present the usual shape observed with As (III) and polyphenols and the determination of $k_{2}$ is related to the measure of the ring current $I_{\mathrm{r}, \mathrm{k}}$ at which the reaction zone just reaches the ring $[3 b]$.

\subsection{Results}

\subsubsection{First-order bromination reactions. With} anisole, $I_{\mathrm{r}}$ versus $I_{\mathrm{d}}$ plots are straight lines as found by Albery, Hitchman and Ulstrup [7]. With phenol, ortho- and meta-cresol, $I_{\mathrm{r}}$ versus $I_{\mathrm{d}}$ traces are slightly curved even at high recording sensitivities, due to the too high bromination rates of these compounds. Nevertheless, we applied firstorder kinetics theory, using the slopes of the curves at the origin.

Table 3 gives the bromination constants $k_{\mathbf{g}}$ observed for anisole, phenol, ortho and metacresol. These are overall constants taking into account bromination by $\mathrm{Br}_{2}$ and $\mathrm{Br}_{3}^{-}$:

$$
k_{g}=\frac{k_{2}^{\mathrm{Br}_{2}}+k_{2}^{\mathrm{Br}_{3}^{-}} \times k \times\left(\mathrm{Br}^{-}\right)}{1+k \times\left(\mathrm{Br}^{-}\right)}
$$

with

$$
k=\frac{\left(\mathrm{Br}_{3}^{-}\right)}{\left(\mathrm{Br}_{2}\right) \times\left(\mathrm{Br}^{-}\right)}=20 \mathrm{M}^{-1} \text { at } 0^{\circ} \mathrm{C}
$$

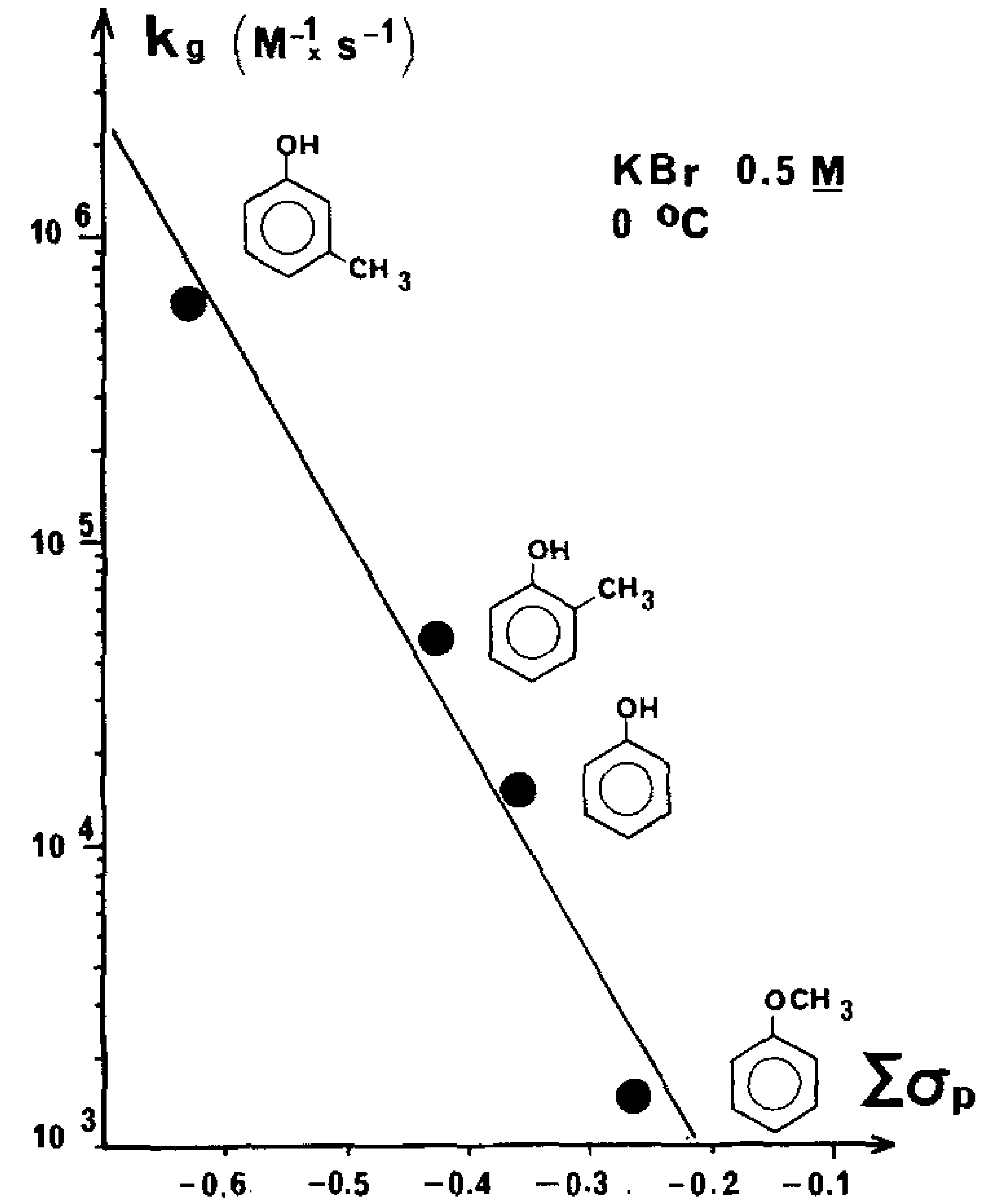

Fig. 7. Correlation between bromination constants and $\sigma_{\mathrm{p}}$ coefficients $(8,9)$ for $\mathrm{m}$-cresol, o-cresol, phenol and anisole. Apparent first order bromination rate constant. Platinum ring-platinum disc electrode (No. 2), $\mathrm{H}_{2} \mathrm{SO}_{4}$ $2 \mathrm{M}, \mathrm{Br}^{-} 0.5 \mathrm{M}$ (except for anisole: $\mathrm{HClO}_{4} 10^{-3} \mathrm{~N}, \mathrm{Br}^{-}$ $0.2 \mathrm{M})$.

In Fig. 7, we have plotted $k_{\mathrm{g}}$ observed for several phenols versus Hammet [8] and Jaffe [9] coefficients for a para bromination. A straight line is observed showing that bromination occurs mainly in the para-position and that the $\sigma_{\mathrm{p}}$ used are suitable to take into account the effects of substituents on the overall reactivity with bromine.

3.2.2. Second-order bromination reaction. Though we have checked the method with allyl-alcohol and recovered data already published [3b] 
(Table 3), no determination of $k_{2}$ was possible for resorcinol, phloroglucinol and orcinol because curves obtained with these phenol differ significantly from the theoretical ones.

\section{Discussion}

Compounds which react rapidly with bromine (resorcinol, orcinol, pyrogallol, phloroglucinol, meta-cresol) can be detected and titrated in very dilute solutions, using ring-disc electrodes. However, these bromination reactions are very complex, especially with dihydroxy 1,3 phenols which undergo several following brominations at different rate-constants, and it is not possible to directly determine the concentration level from the mathematical analysis of the $I_{\mathbf{r}}$ versus $I_{\mathrm{d}}$ curves: this is only possible in the case of a fast bimolecular reaction. Besides, the electrochemical oxidation of the titrated compound on the disc and the detection of its oxidation product on the ring may sometimes interfere with the bromination reaction. So, for these two reasons, titrations should be carried out by comparison of the experimental curves with those obtained with solutions of known concentration.

With phenol, ortho and para-cresol, which react less rapidly with bromine, the sensitivity is somewhat lower and difficulties arise from the oxidation products of these phenols which interfere with the disc-surface when the disc-current is too high.

To conclude; in spite of these difficulties, we think that the use of ring-disc electrodes may be a convenient method for the titration of very dilute solutions of phenols. For example, this method could be used to detect phenolic compounds as pollutants in rivers or in industrial wastes in which they are very often found.

Moreover, we think that ring-disc electrode techniques could lead to the definition of new water pollution criteria such as, for example, an amount of substances reacting rapidly with bromine. Sulphides, thiols, alkyl sulphides and disulphides can be similarly titrated by this method [11].

\section{Experimental}

\subsection{Reagents}

Water was distilled in a glass vessel. Unless otherwise specified, all chemicals used were Prolabo compounds. The following compounds have been used without further purification: sulphuric acid (RP), potassium bromide (RP), triarsenic oxide (RP), resorcinol (RP), orcinol (crystallised), phloroglucinol (RP), pyrogallol (Fluka, pure), hydroquinone (Touzart et Matignon, pure). The following compounds have been distilled under atmospheric pressure: ortho-, meta-, and paracresol, anisole, allyl alcohol (for scientific use).

\subsection{Materials}

A Tacussel bipotentiostat (Bipad type), and a Tacussel monitor (Servovit type) enable linear sweeps of the disc-potential or the disc-current (the ring being set at a constant potential) or linear sweeps of the ring potential (the disc-potential or the disc-current being constant) to be made. The disc- or the ring-potential is measured with respect to a $\mathrm{Ag} / \mathrm{AgCl}$, saturated $\mathrm{KCl}$ electrode (Tacussel, $\mathrm{AgCl} 10$ ) with an electronic millivoltmeter (Tacussel S6 N). A Servogor XY Goertz enables the simultaneous recording of two variables among: ring- and disc-current, ring- and discpotential.

A gold ring-carbon disc electrode (No. 1) was purchased from Tacussel whereas platinumplatinum ring-disc electrodes (No. 2) were constructed by Coquelet (Electricité de France).

Table 2 indicates the characteristics of the ringdisc electrodes. Diameters have been measured from photographic enlargements where a length reference also appeared (slide calipers opened at $1 \pm 0.05 \mathrm{~cm}$ ).

The rotation speed of the direct-current motor which drove the electrode was monitored by a Tacussel Asservitex, between 4 and $80 \mathrm{~Hz}$. The rotation speed was checked with a Jaquet revolution counter.

The $350 \mathrm{~cm}^{3}$ cell used was generally thermostated at $25 \cdot 0 \pm 0 \cdot 2^{\circ} \mathrm{C}$. 


\subsection{Procedure}

The ring-disc electrode surfaces were polished using emery papers before every sequence of recordings, and were submitted to repeated sweeps of potential or current until a reproducible blank was obtained with a solution of potassium bromide. The current or the potential sweep rate was chosen so that scans in the cathodic or the anodic directions agreed with one another (usually $100 \mathrm{~s}$ per sweep). When the disc was monitored for current, the ring-potential was adjusted at a suitable value to obtain a low ring-current background when $I_{\mathrm{d}}=0$. The ring-potential was always low enough to allow the complete reduction of bromide. Under these conditions, the calculated $N_{0}$ is in very good agreement with the observed $N_{0}$ (Table 2). $I_{\mathrm{r}}$ versus $I_{\mathrm{d}}$ blank straight lines may be curved near the origin. This behaviour is more important with the gold-carbon electrode than with the platinum-platinum electrode. With these latter electrodes, this phenomenon is negligible at room temperature but appears clearly at $0^{\circ} \mathrm{C}$.

\section{Acknowledgments}

We are indebted to Dr W. Albery of the University of Oxford for the original suggestion to investigate the applications of ring-disc electrodes to phenol titrations, and to Dr M. Hitchman of the RCA Laboratory in Zurich for helpful discussions.

The authors would like to express their thanks to 'Electricité de France' for financial support of this work.

\section{References}

[1] S. Bruckenstein and D. C. Johnson, Analyt. Chem. 36 (1964) 2186.

[2] W. J. Albery, S. Bruckenstein and D. C. Iohnson, Trans. Faraday Soc. 62 (1966) 1938.

[3] W. J. Albery and M. L. Hitchman, in 'Ring disc Electrodes', Science Research Papers, Clarendon Press Oxford (1971). (a) chap. 9, p. 122 ; (b) chap. 8 , p. 109 ; (c) p. $167-170$; (d) p. 22.

[4] W. J. Albery, M. L. Hitchman and J. Ulstrup, Trans. Faraday Soc, 65 (1969) 1101.

[5] A. W. Francis and A. J. Hill, J. Am. Chem. Soc. 46 (1924) 2503.

[6] F. Rauwel and D. R. Thévenot, Communication to the 'Journées d'Electrochimie' Pau (1973).

[7] W. J. Albery, M. L. Hitchman and J. Ulstrup, Trans. Faraday Soc. 64 (1968) 2831

[8] L. P. Hammett, 'Physical Organic Chemistry', International Chemical Series, McGraw-Hill Book Company, New York (1940) pp. 184-191.

[9] H. H. Jaffe, Chem. Rev. 53 (1953) 191.

[10] R. P. Bell and D. J. Rawlinson, J. Chem. Soc. (1961) 63.

[11] F. Rauwel and D. R. Thévenot, to be published in Bioelectrochem, Bioenergetics 3 (1976). 